une revue Gallia

Rhône-Alpes | 2007

\title{
Lyon 2e « Lugdunum »
}

30 , rue Sainte-Hélène ; Hôtel de Cuzieu

\section{Stéphane Carrara et Catherine Argant}

\section{(2) OpenEdition}

Édition électronique

URL : http://journals.openedition.org/adlfi/6846

ISSN : 2114-0502

Éditeur

Ministère de la culture

Référence électronique

Stéphane Carrara et Catherine Argant, «Lyon 2e « Lugdunum » », ADLFI. Archéologie de la France Informations [En ligne], Rhône-Alpes, mis en ligne le 01 mars 2007, consulté le 19 avril 2019. URL http://journals.openedition.org/adlfi/6846

Ce document a été généré automatiquement le 19 avril 2019

(c) Ministère de la Culture et de la Communication, CNRS 


\section{Lyon $2 \mathrm{e}$ « Lugdunum »}

30, rue Sainte-Hélène ; Hôtel de Cuzieu

\section{Stéphane Carrara et Catherine Argant}

Identifiant de l'opération archéologique : 229692

Date de l'opération : 2007 (SP)

Inventeur(s) : Argant Catherine (COL)

1 Après un diagnostic archéologique positif (C. Becker, SAVL), une fouille préventive a porté sur l'emprise d'une piscine. L'opération archéologique menée par le Service archéologique de la ville de Lyon, sur une surface d'environ $155 \mathrm{~m}^{2}$, a permis la mise au jour, sur l'ensemble de l'emprise de la fouille, de nombreux niveaux et vestiges concernant la période antique, en particulier différentes constructions se succédant de l'époque claudio-néronnienne (50-70) à la seconde moitié du III ${ }^{e}$ s. (vers 220-270).

2 L'opération, a permis de mettre au jour plusieurs sols d'occupation antique, associés à des murs en terre crue (torchis) sur sablière basse, à des murs présentant des fondations maçonnées et des élévations en terre crue, et des bases de pilier maçonnées. Ces vestiges permettent de restituer en partie l'organisation de différents bâtiments au cours des quatre états distingués (Fig. $n^{\circ} 1$ : Base de pilier et mur en terre crue appartenant à l'état 1 de la phase).

3 La première implantation ex-nihilo, datée du troisième quart du $\mathrm{I}^{\mathrm{er}}$ s. apr. J.-C. (50-70), repose à même le terrain naturel correspondant à une nappe alluviale caillouteuse déposée par le Rhône au cours du I ${ }^{\text {er }}$ âge du Fer (800-450 av. J.-C.) (Bravard et al., 1997). Lélévation des bâtiments est réalisée en murs de terre crue reposant pour certains sur des fondations maçonnées, d'autres étant installés sur des sablières basses reposant dans des tranchées de fondation. D'imposants massifs maçonnés, associés à ces murs, supportent des bases de piliers soutenant les charpentes. Les murs et les cloisons de terre crue conservent une partie de leurs enduits : peints à l'intérieur des pièces, blanc côté extérieur. La majorité des sols est en terre battue, seule une pièce présente un terrazzo. 
Les vestiges de l'état 1 semblent appartenir à au moins deux bâtiments aux vocations distinctes : un habitat et des espaces commerciaux de type entrepôt ou boutique (taberna). Le deuxième état d'époque flavio-trajane (70-120) voit la disparition des pièces d'habitation au profit d'espaces plus vastes dont les sols sont en terre battue. L'aspect sommaire de l'architecture (élévations en torchis sur clayonnage) rythmée par des séries de piliers, et son organisation, semblent indiquer l'existence de plusieurs bâtiments (d'axe nord-sud) à vocation commerciale de type taberna ou entrepôt. La multiplication des indices archéologiques permet d'attribuer la destruction de cet état à un incendie dont les traces sont visibles sur toute l'emprise de la fouille, et au-delà (Fig. $n^{\circ} 2$ : Sol de l'état 2 portant les traces d'un violent incendie (parois rubéfiées et effondrées)).

6 Le troisième état, entre 120-140 et 220, peut être subdivisé en deux sous-états. L'état 3a correspond à une phase intermédiaire entre la démolition du deuxième état et l'installation des structures de l'état $3 b$, où l'on retrouve une aire de gâchage et des structures liées à des installations de chantier. L'état $3 \mathrm{~b}$ voit la réinstallation d'un bâti lié à un habitat, alors que persistent un plan et une architecture caractérisant la présence de plusieurs espaces à vocation commerciale, boutiques ou entrepôts.

7 Le dernier état (vers 220-270) concerne l'installation d'un caniveau et de son collecteur mis au jour au sud-ouest de l'emprise de la fouille. Dans la partie est, les espaces commerciaux (entrepôts ou boutiques) semblent perdurer avec toutefois quelques modifications architecturales, mais sans changement de plan ou sans reprises dans le gros œuvre. Quelques éléments archéologiques (fragments de creusets, chutes de bronze) et l'aspect des niveaux de sols paraissent indiquer un travail d'alliages de cuivre et de plomb (confirmé par des analyses) au sein de ce bâti.

8 Une deuxième phase de fréquentation du site, d'époque médiévale et/ou moderne, se manifeste par une série de fosses et deux larges tranchées de récupération ayant perturbé et détruit une partie de l'occupation antérieure.

9 CARRARA Stéphane, ARGANT Catherine

\section{ANNEXES}


Fig. $n^{\circ} 1$ : Base de pilier et mur en terre crue appartenant à l'état 1 de la phase

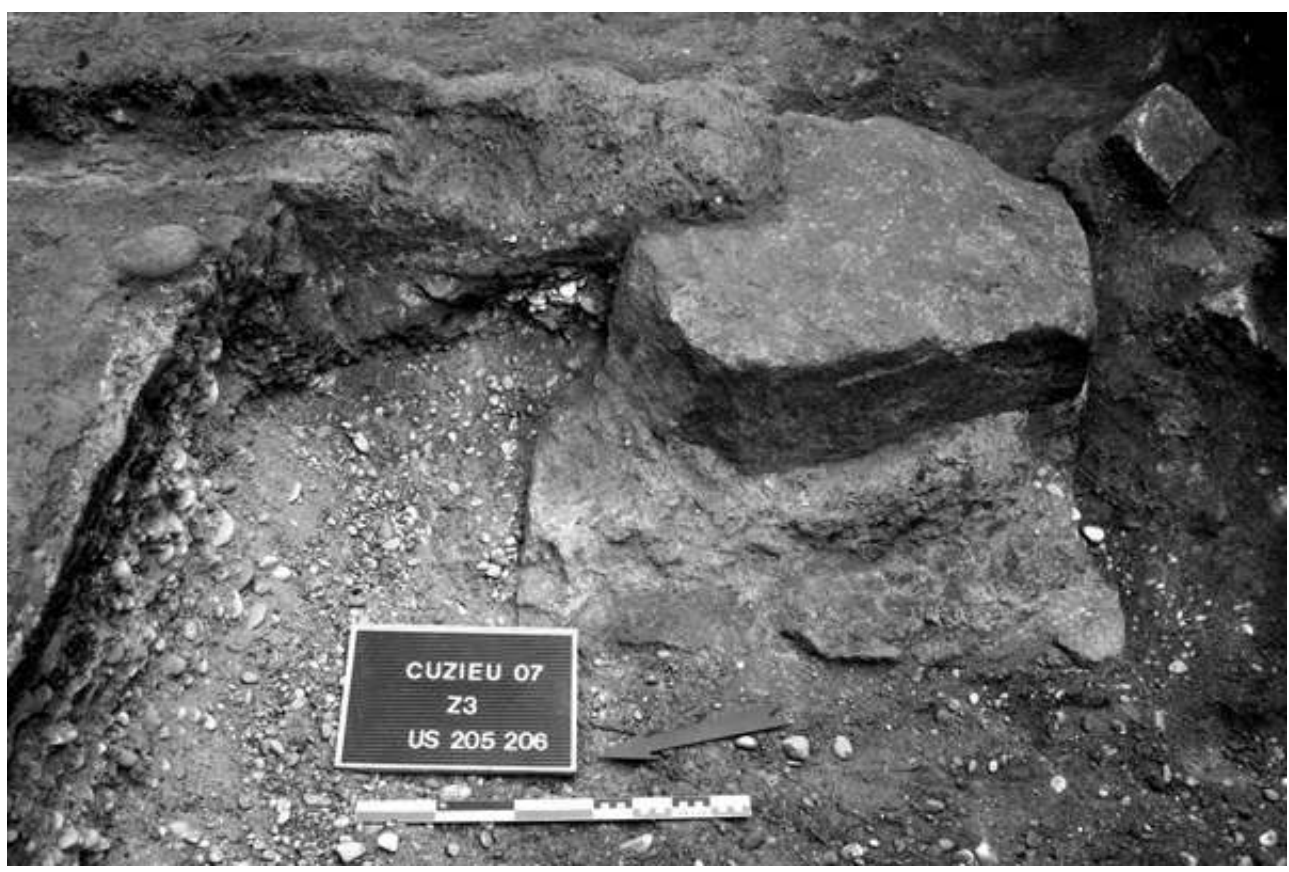

Auteur(s) : SAVL. Crédits : ADLFI (2007)

Fig. $n^{\circ} 2$ : Sol de l'état 2 portant les traces d'un violent incendie (parois rubéfiées et effondrées)

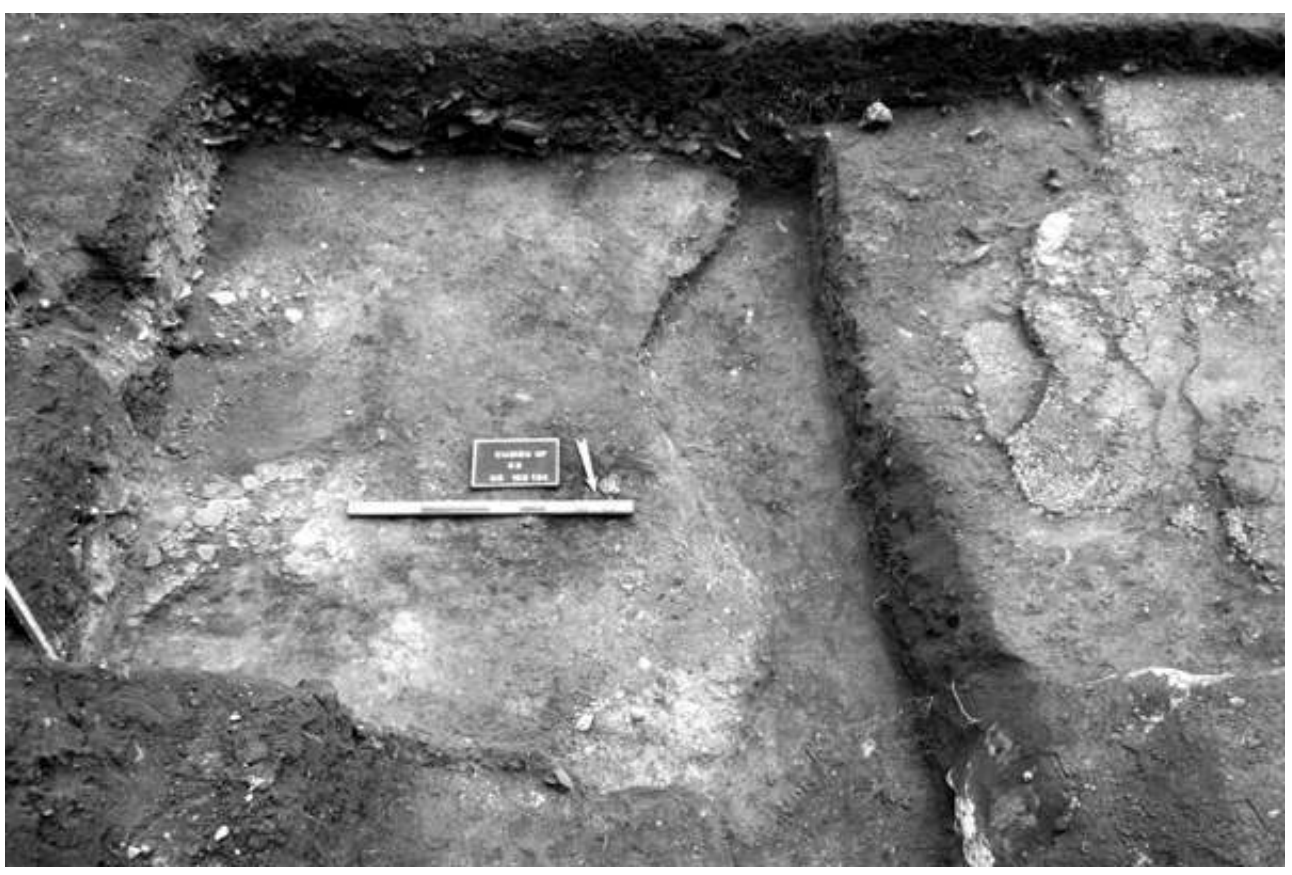

Auteur(s) : SAVL. Crédits : ADLFI (2007) 
INDEX

operation Sauvetage programmé (SP)

Index chronologique : âge du Fer, Empire romain, Moyen Âge*, Ier siècle apr. J.-C., IIe siècle apr. J.-C., Temps Modernes, IIIe siècle apr. J.-C., Haut-Empire

Index géographique : Rhône-Alpes, Rhône (69), Lyon (69123)

\section{AUTEURS}

STÉPHANE CARRARA

COL

CATHERINE ARGANT

COL 